\title{
Tšuktšimaa legendid
}

\author{
Ülo Siimets
}

Pühapäeval, 24. jaanuaril oli pidu. Jõime veini, tantsisime ja ajasime juttu. Töödejuhataja Makarov küsis, kas me oleme kuulnud, kuidas tšuktši karjus võidab endale tšuktši neiu armastuse. Muidugi ei olnud me seda kuulnud ja tahtsime teada. Makarov jutustas:

Kui tšuktši karjus armub tšuktši neiusse, kes ei tee temast välja ega taha temaga abielluda, peab ta ennast peitma jaranga lähedusse või jaranga taha. Ühesõnaga, tüdruk ei tohi teda näha. Kui tüdruk läheb pissile, läheb karjus pärast tüdruku äraminekut lumele jäänud uriinilaigu juurde. Selle loigu juures peab ta lausuma järgmised sõnad:

"Mitte kusi ei kukkunud siia maha. Siia kukkusid maha sinu süda, maks ja neerud."

Siis peab karjus ootama, kui tõuseb Koidutäht. Ta peab tooma ohvri Koidutähele. Aitab väikesest ohvrist, näiteks ohverdab ta kutsika. Rikas mees võib muidugi ohverdada ka põdravasika või põdra. Kui ohver toodud, palub karjus, et Koidutäht annaks talle rautatud saapad, millel on lausa teravad naelad talla all. Pärast seda läheb mees tagasi kuseloigu juurde ja hakkab selle koha peal jalgadega trampima. Sealjuures kordab ta pidevalt järgmisi sõnu:

"Nende saabastega trambin ma sinu südamel.

Nende saabastega trambin ma sinu maksal.

Nende saabastega trambin ma sinu neerudel.

Sa tunned, kuidas minu saapanaelad hammustavad sinu südant, nii kui minu südant tabab valu, kui sa kurameerid teiste meestega.

Sa tunned, kuidas minu saapanaelad torgivad sinu maksa, nii kui sa naeratad teed kallates teistele karjustele.

Sa tunned, kuidas minu saapanaelad torgivad sinu neeru, nii nagu minu omadest käib läbi valu, kui sa ei taha minuga olla."

Neid sõnu tuleb korrata seitse korda. Sõnade lausumise ajal pead jalgu kõvasti vastu maad trampima ja ise seitse tiiru vastupäeva ümber oma telje pöörama. Kui sõnad on lausu-

http://haldjas.folklore.ee/tagused/nr21/legendid.pdf 
tud, pead nõiduse lõpetama, olles näoga Koidutähe poole. Sa teed Koidutähele sügava kummarduse ja lubad, et kui ta sinu palve täidab, tood talle uue ohvri. Seejärel lähed tagasi oma jarangasse ja heidad magama. Kui esimesel korral asi ikka ei laabu, viid tseremoonia läbi veel kord. On kindel, et pärast kolmekordset riituse läbiviimist on tüdruk sinusse armunud. Tavaliselt aitab muidugi ühest korrast.

Reede, 26. veebruari õhtul ei olnud elektrit. Me ei saanud süüa teha ja läksime Niina juurde, kus küdes pliit ja valgust andis petrooleumilamp. Sinna saabus ka Kolja. Ajasime juttu.

Küsisin Koljalt: "Sa liigud mööda Magadani oblastit palju ringi. Ega sa ole kuulnud šamaanide huvitavatest maagilistest võimetest või eriskummalistest juhtumustest?"

Kolja vastas, et praegusest ajast ei tea ta erilisi juhtumeid, aga võib rääkida ühe loo lapsepõlvest. Ja ta jutustas:

Kui ma olin noor poiss, jutustas vanaisa mulle ühe imeliku loo. See kõlas nii:

Ühel vanal šamaanil, ta nimi oli vist Jelöpal, läks halvasti. Inimesed ei uskunud enam teda, sest kõik tema ennustused ei läinud nii, nagu ta oli rääkinud. Inimeste usku vähendas veel põdrakarjaomanik, kes oli šamaani solvanud, öeldes, et tal ei ole enam võimeid ja üldse on ta üks kasutu tudi ning parem on, kui ta tema jarangade juurest jalga laseb.

Teised karjused naersid šamaani üle. Jelöpal sai muidugi vihaseks ja karjus tšuktšidele, et naerge aga naerge. Veel enne, kui täiskuu jõuab teist korda taevasse, on minu mõnitaja surnud, ilma et ma peaksin oma käe tema vastu tõstma.

Niisiis ei olnud šamaanil oma võimu taastamiseks muud teha, kui ta pidi oma ähvarduse täide viima. Ainukeseks võimaluseks jäi kasutada musta ehk teisiti öeldes kurja maagiat. Selliste rituaalide läbiviimine on väga ohtlik, sest kui sa millegagi eksid, tabab needus sind ennast.

Rituaali läbiviimiseks oli šamaanil vaja täiskuu abi. Muud tal siis teha ei jäänudki, kui vaikselt omaette kiruda ja oodata. Lõpuks saabus täiskuuaeg. Taevas oli selge. Tähed sirasid ja kuu oli taevas nagu suur kollane ketas. Śamaan oli juba varakult alustanud oma rituaalidega pühas ehk "pimedas" jarangas. Tema bubini põrin kaikus raevukalt tundra kohal ning kuulda oli tema kriiskeid ja karjeid. Tavaliselt olid 
šamaani toimingutest osa võtnud ka teised, aga seekord viis ta rituaali läbi täiesti üksi. Inimesed kõrvaljarangades ei saanud magada. Aeg-ajalt muutusid karjed hästi kiljuvaks, aegajalt oli kuulda tumedat pobinat. Sama oli ka bubini põristamisega. Ka selle tagumine käis lainetena. Vahel oli kuulda kiiret peenikest kôla, vahel kostsid harvad tumedad mütsud.

Keskööl vaikis trummipõrin. Üks karjustest, kes enne ei julgenud välja minna, läks õue vett laskma. Kui ta oli põie tühjendanud, kuulis ta šamaani jaranga juurest hääli. Ta piilus oma jaranga tagant ja nägi oma imestuseks neljakäpakil kõndivat Jelöpalit. Mees oli täiesti alasti. Ainsaks riietusesemeks oli šamaanil loomade peanahkadest tehtud müts. Jelöpal kõndis neljakäpakil tundrasse otse kuu suunas.

Karjus ei olnud kõikidest sõnadest aru saanud, aga põhimõte oli selline:

"Oo kuu, kuu. Sina, kes sa valitsed ööd.

Sina, kes sa oled suuteline pimeduse katkestama, aita mind.

Sa näed, kuidas ma alandlikult rooman sinu ees.

Mul ei ole saladusi sinu ees, ma näitan sulle täielikult oma keha. Aita mind.

Aita mul saada jagu vaenlasest. Ta on alandanud mind. Ta on teinud mu teiste ees naeruväärseks. Halasta mulle. Ma olen sulle alati ohvreid toonud ja kui sa mind aitad, siis toon ma neid ka edaspidi.

Aita leevendada minu raevu. Tee nii, et minu vaenlane sureks."

Edasisest ei saanud karjus aru, sest šamaan roomas liiga kaugele ja ta ei julgenud jaranga varjust välja tulla.

Oli kuidas oli, aga nädal hiljem oli šamaani solvaja haige. Ta eluküünala leek muutus lausa silmanähtavalt üha hädisemaks ja paar nädalat hiljem oli mees surnud. Ta surnukeha viidi tundrasse ja põletati tuleriidal ning ohvriks toodi rikkalikult põhjapõtru, et needusega tapetu ei tuleks halva vaimu ketljana elusaid kiusama. Matuserituaali viis läbi loomulikult šamaan, kes oli nü̈̈d oma au taastanud.

Imelik oli see, et kuigi šamaan oli selle rituaali läbiviimise ajal vana mees, elas ta veel väga kaua. Ta oli pärast vaenlase surma koguni nooremaks muutunud, nagu oleks ta selle tseremoonia läbiviimisega endale ka noorema mehe elujõu saanud. Inimesed aga kartsid meest, kuni ta lõpuks hinge heitis. 
Veel kaua aega ohverdati igal aastal tema laiba põletamise kohal põhjapõder pahade vaimude ketljade kurjuse leevendamiseks.

Need olid muidugi vana aja mehed. Tänapäeval selliseid enam vist ei leidu.

Siis tuli elekter tagasi, mängisime natukene kaarte, aga ei viitsinud kaua külas olla, sest mina pidin hommikul tööle minema.

Järgmistes lugudes juurdleb Vladimir Bogaras-Tan sugulastevaheliste abielude üle ning esitab kaks juttu õe ja venna abielust - loomismüütide tšuktši versioonid. Ta kirjutab:

Abielu onu ja vennatütre vahel peeti lubamatuks. Ometi on mulle teada üks juhtum, kus onu oli oma vennatütrega salajases vahekorras, ning teine lugu, kus tšuktš abiellus oma vennatütrega kõikide pulmakommete järgi. Muuseas pean ütlema, et tema naabrid naersid sellepärast tema üle. Mulle on teada ka kaks juhtumit isa ja tütre kooselust. Abielu või armuelu õe ja venna vahel peetakse verepilastuseks. Kuid paljudes juttudes "Esimese maailmaloomise aegadest" (tot-tomgattagnep), nendes, mis jutustavad maailma ja inimese loomisest, kirjeldatakse õe ja venna abiellumisi väga üksikasjalikult. Nii on ühes jutus kirjas, et esimene inimeste paar sünnitas algul poja, siis tütre. Lapsed istusid jaranga sissekäigu juures ja kasvasid. Ema ei hoolitsenud nende eest ja nad kasvasid järelevalveta. Siis vend abiellus õega. Neil olid lapsed. Nende poeg abiellus teise tädiga. Nii nad paljunesid ja inimesi sai palju, aga kõik nad jäid vendadeks.

Teises jutus meenutatakse Lurenimaad, mis asus mere kaldal. Seda maad meenutatakse mitmes jutus nagu maad "esimese loomise aegadest". Jutustus räägib, et mereäärne rahvas, kes elas sellel maal, suri nälga. Ellu jäid ainult kaks inimest - täiskasvanud õde ja poisiohtu vend. Õde toitis venda peeneks tambitud lihaga. Kui poiss kasvas, palus õde, et noormees abielluks temaga.

"Kui sa ei minuga abiellu, siis meil ei ole lapsi," ütles õde. "Meil ei ole järglasi ja maa jääb inimesteta. Teisiti inimesi luua ei saa. Ja kes meid ikka näeb? Kes meid näeb ja ütleb meile "Häbi!"? Kes terves maailmas sellest teada saab...? Me oleme täiesti üksi maa peal.” 
Vend vastas: "Ma ei tea. Ma tunnen, et see oleks paha. See on keelatud."

Siis õde hakkas mõtlema: "Kuidas ma seda teeksin? Meie suguvõsa hävib koos meiega."

Järgneb jutustus sellest, kuidas noor naine läks oma jarangast kaugele. Ta ehitas uue jaranga. See ei sarnanenud üldse nende omaga. Ta tegi kõik uued majapidamisriistad ja ka uued rõivad. Siis läks ta koju tagasi ning ütles vennale, et nägi kaugel mere kaldal kellegi jarangat. Vend läks seda otsima ja lõpuks leidiski. Õde oli juba seal. Ta vahetas oma rõivad, muutis näoilmet ja häält. Vend ei tundnud teda ära ja pidas teiseks naiseks. Pärast mõningast kõhklust võttis ta tüdruku naiseks. Siis algas elu kahes jarangas: õde oli siin ja seal ning täitis edukalt mõlemat osa.

Pärast seda, kui naine rasedaks jäi, ei mõelnud vend enam õe peale ning jäi elama uude elupaika. Nendel sündis üks laps, siis teine. Pere suurenes ja suurenes. Nendest põlvnesid kõik inimesed, kes nü̈̈d elavad külades ja karjade peatuspaikades (Bogoras-Tan 1934: 118-119).

Samasuguseid arhailisi müütilise ja usundilisi motiive sisaldab pool sajandit hilisem Maksimi jutustus. Muinasjutt sisaldab mitmeid olustikulisi detaile:

Tšuktšimaa tundras elas põdrakarjus. Alaealiselt pandi ta paari naaberkarja omaniku tütrega. Elu kulges oma tavalist rada pidi. Põhjapõdrakari kasvas, aga suureks õnnetuseks oli see, et naine ei jäänud käima peale. Küll kutsus mees endale uusi noori mehi külla, aga midagi ei juhtud, naine oli ikka lastetu.

Mehel ei jä̈̈nud muud üle, kui võttis jarangasse teise, noore naise.

Kui mees võttis teise naise, hakkas ta üha vähem hoolima oma vanast naisest. Ta armatses ja magas noore naisega üha rohkem. Noor naine kiusas pidevalt vana naist ja käskis tal igal hommikul kusepotti välja viia.

Ükskord sai vanal naisel hing täis ja ta keeldus seda tegemast. Noor naine kallas talle oma kusepoti kaela. Vana naine kaebas mehele. Vastuseks mees ainult sõimas teda ja ütles, et sul, lastetul, ei ole mingit vastuvaidlemisõigust. Vana naise magatamine jäi üha harvemaks. Vanale naisele asi ei meeldinud ja ta hakkas oma mehele esitama pretensioone. 
Olukord muutus vana naise suhtes katastroofiliseks pärast seda, kui noor naine sünnitas peremehele pärija, ilusa poisslapse. Pärast seda ei läinud mees enam üldse ööseks vana naise juurde. Kui naine protesteeris, hakkas mees vana naist peksma. Peks läks üha hullemaks. Lõpuks sai ta mehe käest müksu iga kord, kui ta talle vastu juhtus.

Lõpuks ei kannatanud naine enam peksu välja ja põgenes tundrasse. Ta hulkus kaua ringi, toitudes marjakestest ja juurikatest. Kalade kudemise ajal jõudis ta jõe äärde. Kudemisele kiirustavaid kalu oli palju. Vesi lausa kubises nendest. Naine pü̈̈dis kalu ja ta kõht oli pidevalt täis. Jõe ääres oli kaladega toitumas palju karusid. Karudel oli kõht täis ja nad ei puutunud kalu pü̈̈dvat naist.

Kudemisaeg lõppes. Ilmad läksid külmemaks. Karud kadusid jõe äärest oma koobastesse. Naine leidis ühe karukoopa ja läks sinna sisse. Emakaru urises ja paljastas hambad. See oli üks nendest karudest, kes naisega koos jõe ääres kalastasid. Naine ütles talle:

"Miks sa ei tapa juba mind. Mees kogu aeg peksab mind, ma ei saa koju minna, parem tapa mind ära."

Karu tundis vist naise ära ega murdnud teda maha. Naine jäigi karude juurde elama.

Üks karudest oli libakaru. Ta oli šamaan, kelle paha vaim ketlja oli muutnud karuks, kes aga aeg-ajalt võis siiski inimesena ringi käija. Tuli kevad, naine tahtis koju minna. Libakaru õpetas talle mitmesuguseid manamisi ja loitse. Naine sai selgeks, kuidas ennast karuks muuta ja kuidas hiljem jälle inimeseks saada.

Naine läkski siis koju tagasi. Ta hulkus karuna kodu ümber ringi. Ükskord kohtas ta oma meest tundras. Karu ründas teda ja tahtis maha lü̈a. Mees hakkas hirmuga paluma, et karu ei tapaks teda. Karu sõnas inimkeeli, et kui sa võtad oma vana naise koju tagasi ja ei peksa teda ning kihutad noore õela naise minema, jätan ma sind ellu. Mees lubas seda teha. Karu urises ta peale hirmuäratavalt ja sõnas, et kui sa mind petad, siis tulen ja tapan su ära.

Mees läks hirmuga koju. Karu muutis ennast uuesti naiseks ja kiirustas jarangasse. Mees oligi juba oma noorest naisest tüdinud, sest kui tol ei olnud vana naist kiusata, hakkas ta kiusama meest ja irises pidevalt tema kallal. Vana naine 
saabus tagasi saleda, ja nagu mehele tundus, väga ilusana. Võib-olla oskas naine libakaru õpetatud loitsudega meest mõjutada. Naise silmad pildusid kelmikaid välke, nii et mehel jalad lausa nõrgaks läksid. Ka naeratas ta oma mehele, kes ei olnud viimasel ajal oma nooremalt naiselt lahkeid sõnu kuulnud.

Vana naine võitis oma armastuse tagasi. Tegelikult ei olnud ta ju vana, ta oli ainult mõni aasta nooremast naisest vanem. Mees ajas võistlejanna, noore naise, jarangast välja, kus see näljast ja külmast hukkus.

Innokenti jutustus ebatavalise kogemuse ja häälte nõuannete abil šamaaniks saamisest sisaldab lisaks paljusid uskumusi, rituaalikatkeid ja muinasjutumotiive:

See lugu on ammustest aegadest.

Peveki lähedal on kalju, mida tuntakse šamaani kaljuna. Tema tipp mattub alati uttu. Kui mujal kaljude peal pesitsesid linnud, siis selle kalju juures ei olnud neid kunagi. Selle kalju juurde ei viinud isegi metsloomade rajad. Tema juures oli kuulda ainult surmavaikust. Samas loksub selle püstloodis kalju jalamil rahulik meri.

Kalju lähedal all orus asuvas külas elasid tšuktšid ning elavad seal ka praegu.

Kalameeste ja jahimeeste paadid läksid merele ning tulid tagasi enamasti saagiga. Naised olid töökad. Nad puhastasid saagi kohe kaldal. Lapsed ja koerad olid söönud ja jooksid rahulikult ümbruskonnas ringi.

Seal elas kord šamaan Kelewgi, kelle kõige tähtsamaks ülesandeks oli kaitsta inimeste maailma halbade vaimude sissetungi eest. Samas oskas ta ka ennustada. Šamaan ütles all külas elavatele jahimeestele, millal on õige aeg minna tundrasse, et küttida metsikud põhjapõtru. Ta teadis, kus olid hirmutamata metsikud põhjapõdrakarjad. Jahimehed läksid tema soovituste järgi ega jäänud kunagi saagita.

Šamaan oskas alati öelda, millal on õige aeg küttida väikesi ja suuri loomi. Tema ennustused läksid alati täide. Ta teadis, kus asuvad sooblid, oravad ja nirgid. Isegi ahmide asukoha mä̈̈ras ta õigesti.

Šamaan elas kogu aeg üksi. Ta oli nii vana, et keegi ei mäletanud, kui vana ta on. 
Ta oli šamaaniks saanud alles siis, kui oli juba üle keskea. Tema saatuse määras ohtlik seiklus, mis juhtus siis, kui ta viibis hülgejahil. Kelewgi seisis pika laia jääprao ääres. Tal õnnestus visata harpuun veest pea välja pistnud, õhku hingama tulnud, hülgesse. Harpuuniga õnnestus tal raiuda lahti üks jäätükk, ning kasutades pootshaaki nagu aeru, hakkas ta sõudma hülgekeha suunas.

Ta oli juba üsna hülge lähedal, kui ranniku suunast hakkasid puhuma tugevad tuuleiilid. Need kandsid jääpanga koos Kelewgiga rannikujääst eemale. Mees lõi oma harpuuni tugevalt jäässe, sidus nööri ühe otsa harpuuni ja teise otsa keha külge. Kahe käega hoidis ta kinni harpuunist. Meri muutus tormiseks ja jääpank lendas lainetel üles ja alla. Lained rullusid üle panga ja Kelewgi riided jäätusid. Mõne tunniga hakkas tal nii külm, et ta otsustas piinad enesetapuga lõpetada. Ta oli tõmmanud juba noa tupest välja, kui kuulis kedagi rääkivat:

"Ära tapa ennast. Varsti oled sa tagasi kodus."

Siis nägi Kelewgi, et torm murdis lahti suure jäämäe, mis talle kiiresti lähenes. Jäämäe üks serv oli madal ja Kelewgil onnnetus kerge vaevaga pangalt jäämäele üle kolida. Keset jä̈̈mäge oli palju lahtisi jäätükke, mis moodustasid midagi koopataolist. Mees ladus lahtisi jäätükke veel juurde ja sai endale jä̈̈st elamu.

Ootamatult muutis ka tuul suunda ja jäämägi lähenes vees loksuvale tapetud hülgele. Kelewgil onnestus loom pootshaagiga veest välja tõmmata. Ta võttis tapetud hülgelt naha ja sai sellest oma ebatavalisse jääst elamusse vaiba. Koopas võttis ta riided seljast ja väänas need hoolikalt välja. Uuesti riietunud, tõi ta esimesena ohvri vaimule, kes oli ta päästnud. Ta viskas merre hülgesilma, tükikese peaaju ja teise maksa. Järgnevalt sõi ta ise teise hülgesilma, looma ajud ja maksa. Mitme päeva jooksul tarvitas ta toiduks vaid hülgerasva ja hülgeliha. Vett limpsis ta jäätükkidelt.

Siis torm rauges. Tuul muutis jälle suunda ja jääpank lähenes rannale. Tal õnnestus kaldale pääseda. Koju jõudes tõi ta uuesti ohvri end päästnud vaimule. Kodused pidasid teda halvaks vaimuks, sest sellisesse olukorda sattunu ei olnud kunagi eluga tagasi pöördunud. Ta oli sunnitud kodust lahkuma. 


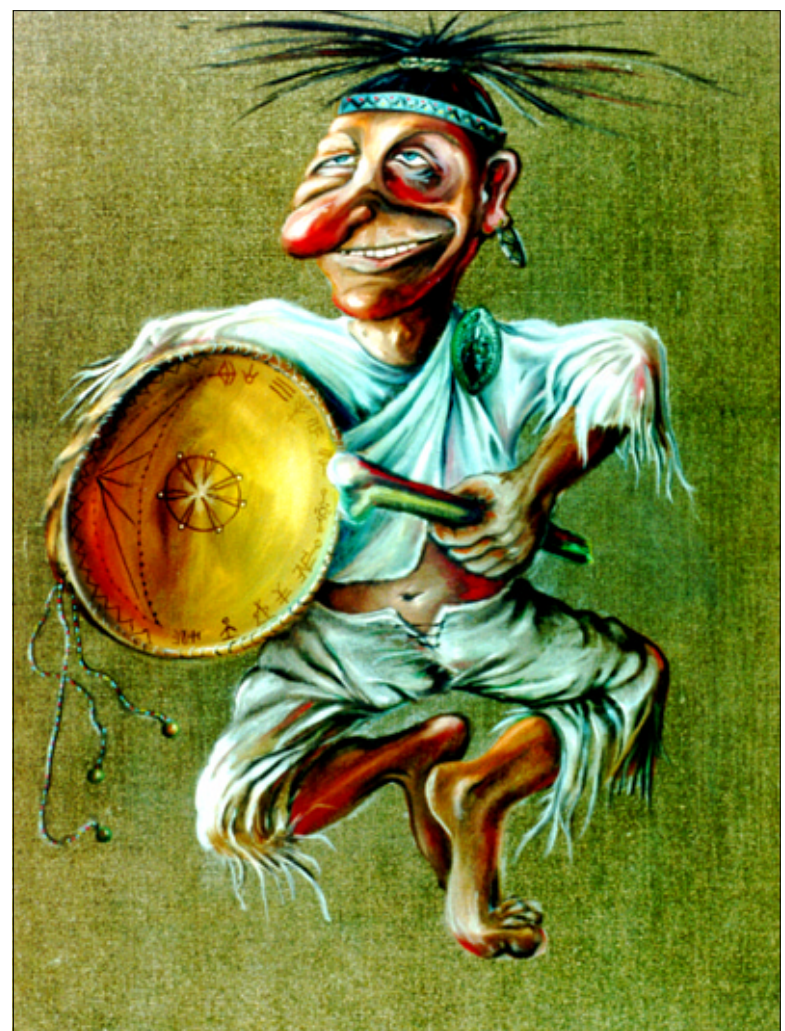

Erki Evestus. Šamaan on kõikide inimeste sõber. Maal Eesti Rahva Muuseumi näituselt 2000.aastal.

Pärast seda hakkas ta kuulma hääli, mis talle nõu andsid. Nad käskisid tal minna elama küla lähedale mäele ja ta tegigi seda. Rituaale sooritades ja bubinil trummeldades õnnestus tal alati leida sobivaid vaime, nii all- kui ka ülalilmast. Ta tuli nendelt hingeretkedelt alati õige sõnumiga tagasi.

Šamaan oli ehitanud oma jaranga kaljuveerule halbade vaimude ketljade ja inimeste maa piirile. Seal oli tavaliselt alati vaikne. Tema jarangast kõrgemal ei kasvanud enam rohi, ei ôitsenud lilled ja kaljusid ei kaunistanud isegi õitsev sammal. Talvel ei jäänud lumi sinna püsima ning tundus, et isegi tuul pü̈̈dis lahkuda sellest piirkonnast kiiremini kui mujalt. Ta oli oma jaranga ülesse pannud "surmamaa" piirile, et olla 
vaimudele lähemal ja alati kohal, kui inimesi on vaja kaitsta halbade vaimude eest. Sellepärast kutsusid inimesed teda Kelewgiks, mis tšuktši keeles tähendab vaim-inimest.

Aga all orus laulsid suvel linnud. Seal vulisesid ojad, lõhnasid lilled ja terve org oli täis õitsvat sammalt.

Talvel mattus tundra lumme. Lumele jäid lindude ja loomade jäljed. Ka nartad jätsid lumele oma jäljed, kui tšuktšid käisid jahil või külastasid oma hõimlasi. Külaskäikude ajal oli kuulda jarangadest naeru, trummipõrinat ja ülemeelikuid hõikeid.

Õhtuti viis šamaan läbi oma rituaale ja tema bubini mäng kostis all orus elavate inimesteni. Sageli vaatas šamaan ülevalt all orus tunglevaid inimesi. Ta ei tundnud rahvahulki vaadates kadedust ega rõõmu, hirmu ega vihkamist. Talle lihtsalt ei meeldinud suured inimhulgad, talle ei meeldinud liigne kära.

Ometi tuli ta alla inimeste juurde, et viia läbi pidulikke ohvritalitusi noore põdra pühal või rituaale, nagu näiteks põletusmatustel.

Ta teadis, et põletusmatustel viib laibapõletuslõkke suits kadunu hinge otse taevasse. Ta õpetas tšuktšidele, et matustel peab olema tasa. Kui matuste ajal on näha tuulispaska, peab teraselt kuulatama. See on lahkunu hing, kes sinust kiiretel põhjapõtradel mööda kihutab. Kui sul õnnestub haarata möödakihutavate põhjapõtrade suitsetest, oled sa tehtud mees. Sa saad põhjapõdrad endale ja nendega maapealsed loomad ei suuda kiiruses võistelda.

Kelewgi oli õpetanud tšuktšidele, et austage virmalisi, sest seal üleval on paljude surnute hinged. Need on ootamatult või vägivaldse surma tõttu lahkunute hinged, kes ei ole saanud rahu. Valged triibud ja täpid on katku või muusse nakkushaigusse surnute hinged, punased triibud ja täpid on noaga tapetute hinged, tumedad täpid ja laigud on psü̈hilise haiguse tagajärjel siitilmast lahkunute hinged. Erineval viisil tapetutel on oma värv ning kuna need hinged ei saa rahu, virvendab valgus kogu aeg.

Kuna Kelewgi õpetused loomade asukoha määramisel olid alati õiged, tõid jahimehed talle igast saagist teatud osa. Naised õmblesid talle rõivad selga ja jalanõud jalga.

Kelewgi juures ei olnud keegi kunagi külas käinud. Teda kutsuti alati eemalt inimestele appi. Tagasi minnes anti talle toitu ja riideid kaasa. 
Möödusid aastad aga miski ei muutnud väljakujunenud korda.

Ükskord kuulis šamaan kaugusest lapse nuttu. Hääl kaikus mägede vahel ja Kelewgi ei saanud algul aru, kust see tuleb. Ta läks õue ja kõndis ringi. Siis taipas ta, et nutt kostab mäe tagant inimeste ja vaimude maa piirilt. Ta ruttas mäe taha ja jõudis kohale viimasel hetkel, sest järgmise sammuga oleks laps astunud üle surmamaa piiri ja muutunud kiviks. Ta haaras lapse sülle ja viis oma jarangasse.

Ilmad olid läinud juba halvaks. Šamaan ei saanud lapsega enam mäest alla ja laps jäi talveks tema juurde. Kelewgi imestas, kuidas laps oli mäest üles saanud. Ju olid teda kaitsnud head vaimud.

Talve jooksul harjus ta lapsukesega ning hakkas teda armastama. Laps oli veel nii väike, et ei mäletanud oma vanemaid. Saabus kevad. Šamaan külastas orus asuvat küla, aga keegi ei meenutanud kadunud last. Ääriveeri küsis ta siit ja sealt, aga keegi ei teadnud midagi. Last nagu polekski olnud. Ju on see vaimude kingitus mulle, mõtles Kelewgi ja pani lapse nimeks Kingitu.

Talv vaheldus kevade, kevad suvega. Sügisest sai jälle talv. Nii möödusid aastad. Kingitu ei olnud kunagi jaranga juurest lahkunud. Ta oli kogu aeg elanud ainult koos šamaaniga. Talle oli selgeks saanud, kus asub elumaa ja surmamaa piir, aga ta ei olnud kunagi näinud teisi inimesi.

Ükskord lendasid kaljule kaks linnukest. Nad laulsid ilusti. Tüdruk jooksis jarangast õue neid vaatama. Linnud ehmusid, lendasid surmamaa suunas ja kukkusid kividena alla.

"Mis need olid?" küsis Kingitu.

"Linnukesed," vastas Kelewgi.

"Kust nad tulid?"

"Alt orust, inimeste juurest."

"Kes on inimesed?"

"Need on nagu meie, aga neid on all orus palju."

"Mida need linnukesed tegid?"

"Nad laulsid armastusest."

"Mis on armastus?"

"Sul on vara sellest teada," vastas šamaan.

Läksid veel aastad. Kingitu kasvas kauniks ja sihvaks tüdrukuks. 
Aeg-ajalt käis Kelewgi all külas. Ta viis seal läbi rituaale ja tõi vastutasuks toitu ja rõivaid.

Ühel kevadel lendasid kaljule kaks kuldkollast liblikat. Nad lendasid siia-sinna. Hõljusid siin ja seal. Kingitu oli õuel päikese käes ja ta imestas, et mis asjad need on.

Kelewgi tuli õuele, vaatas ja ütles: "Need on liblikad."

"Mis nad teevad?"

"Nad mängivad armumängu."

"Mis see on?"

"Sul on vara sellest teada," vastas šamaan.

Tüdruk pü̈̈dis liblikaid lähemalt vaadata. Need ehmusid, tõusid kõrgemale ôhku. Tuulehoog kandis nad üle surmamaa piiri ja nad kukkusid kividena alla.

"Kust nad tulid?"

"Alt orust, inimeste juurest. Seal on neid palju."

"Võta mind inimeste juurde kaasa, kui sa alla lähed."

"Sul on veel vara nende juurde minna," vastas šamaan.

Möödusid suvi ja sügis. Tuli uus talv. Terve talve palus tüdruk, et Kelewgi teda orgu kaasa võtaks. Lõpuks jäi vanamees nõusse. Nad käisid all orus. Tagasi tulles rääkis tüdruk Kelewgile päevade kaupa, kui ilus oli inimeste juures.

Hiljem hakkas ta käima üksinda inimeste juures. Tavaliselt saabus ta tagasi kaasa pandud toidu või riietega. Ükskord tõi ta kaljule kaasa lilli. Ülal kaljul oli külm ja lilled närbusid. Tüdruk kurvastas ja hakkas nutma.

Kelewgi võttis lilled ja viskas nad üle surnumaa piiri. Lilled kukkusid maha ja muutusid kiviks.

Järgmisel suvel läks Kingitu jälle alla orgu. Ükskord sügisel korjas ta tagasiteel murakaid. Ta tõi neid korviga kaasa ka Kelewgile. Ülal oli kalju juba külm ja marjad külmusid. Nad muutusid kõvaks kui kivi ega kõlvanud sü̈a. Tüdruk hakkas nutma. Ta viskas marjad üle surmamaa piiri. Need kukkusid maha ja muutusid kiviks.

Tüdrukust oli kaunis neiu saanud. Ikka käis ta inimeste juures, aga alati tuli õhtuks koju.

Ühel ôhtul aga Kingitut ei tulnud. Hommikul läks Kelewgi teda otsima. All orus ôitsesid lilled, laulsid linnud ja lendlesid liblikad. Kaugusest kuulis ta neiu naeru. Ta hiilis lähemale ja nägi Kingitut armatsemas kauni tšuktši põdrakarjusega. 
Kelewgi ohkas. Ta sai aru, et Kingitul on aeg inimeste juurde jääda. Vanamees vantsis mööda rada üles jaranga juurde. Terve päeva ootas ta Kingitut, aga teda ei tulnud. Suures meelehärmis astus ta üle surmamaa piiri ja muutus kiviks.

Tüdruk tuli jaranga juurde. Ta naeris ja otsis Kelewgid, tahtes jutustada talle, et ta sai teada, mida tähendab armastus. Lõpuks läks ta jaranga taha ja nägi, et kivistunud šamaan seisab teisel pool elu ja surmamaa piiri. Kingitu sai aru, mis oli juhtunud, aga teha ei olnud midagi.

Ta läks inimeste juurde ja abiellus põhjapõdrakarjusega. Hulk aastaid valendas mäe otsas kaljul Kelewgi jaranga, kuni see lõpuks aja jooksul lagunes.

Šamaanikaljut võivad aga kõik veel praegugi näha.

Vladimir Bogoras-Tanil on ka üks karuks moondunud naise lugu, mis tundub olevat eespoolse karuloo teisend. Ta kirjutab:

Ühes tšuktši jutus hülgas mees naise ja viis last ning läks noore naise juurde. Naine hankis endale suure vaevaga toitu, korjates söödavaid juuri. Mööda tundrat rännates jõudis ta kord mere kaldal asuva elamu juurde. Ukse juures istus naine, kelle mees oli just jõudnud jahilt tagasi ja toonud jarangasse hülge. Hüljatud naine tundis selles mehes ära oma mehe ja otsustas kätte maksta.

Ta ootas, kuni mees väljus, ning läks siis jarangasse. Seal sõbrunes ta mehe uue naisega ning kui naine uinus, tappis ta ära. Seejärel läks ta oma koju tagasi. Kui mees jahilt saabus, nägi ta, et tema uus naine on tapetud. Mees sai kohe aru, et see on tema esimese naise kätetöö. Ta haaras oda ja siirdus vanasse jarangasse. Kui ta kohale jõudis, ei olnud kodus naist, sest ta oli läinud jälle juurikaid otsima.

Lapsed kisasid: "Isa tuli, isa tuli!"

"Kus on teie ema?"

"Mööda seda rada tuleb edasi minna. Me jookseme talle järele."

"Ei, ei. Oodake mind siin."

Mees läks ja jõudis jõe äärde. Naine korjaski juuri.

"Nü̈̈d ma leidsin ta üles ja tapan ta ära," mõtles mees ja karjus:

"Ma tapan su ära!" 
Naine hakkas mööda kallast jooksma ja küsis: "Miks sa pead mind ära tapma? Kas sa ei ole minu mees? Mul on väikesed lapsed."

"Miks sa naersid minu üle?"

Mees vehkis odaga. Naine haaras odast ja murdis selle tükkideks. Siis tõmbas ta kapuutsi üle pea, muutus karuks ja tormas mehe kallale.

Mees hakkas paluma:"Oi, palun sind, lase mind lahti. Lähme koju. Ma hakkan alati sulle toitu tooma ja tööd tegema.”

Vastuseks naine ainult möirgas ja rebis mehe tükkideks (Bogoras-Tan 1934: 133-135).

See muinasjutt on väga populaarne. Ameerika eskimode juures kirjutas analoogse jutu üles Edward William Nelson.

Mutluwgi poeg pü̈̈dis väikese kreveti. Tõi kreveti koju. Võttis natukene heina, punus sellest pika patsi ja kleepis krevetile pähe. Seda tehes tõukas ta krevetti jalaga. Krevett muutus kauniks, pika, paksu patsiga tüdrukuks. Mees ütles neiule:

"Mine magamispologi!"

Tüdruk läkski. Enne öö saabumist tulid koos Hommikuvalgus ja Õhtuvalgus.

"Ohoo, kes seal on?"

"Need oleme meie."

"Kes teie? Miks te tulite?"

"Me tahame sinu naist."

"Minu naise asemel võtke see naine, minu õde."

Õhtuvalgus ütles: "Hästi, võtame siis kas või selle naise. Luba meil minna magamispologi. Luba meil abielluda."

"Ei, ei. Ärge minge magamispologi. Minge koju ja võtke mu õde kaasa. Magage temaga oma kodus."

"Hästi, oleme nõus."

Naine tuli jarangast välja. Õhtuvalgus ja Hommikuvalgus haarasid temast kahelt poolt kinni ja viisid koju. Tee peal ütles Õhtuvalgus: "Mina heidan temaga esimesena magama."

Hommikuvalgus vastas: " $\mathrm{E} i$, me mõlemad heidame temaga korraga magama."

Nad jõudsid koju. Hommikuvalgus ütles: "Keedame algul sü̈̈a.”

Õhtuvalgus vastu: "Heidame algul magama. Las naine heidab ka meiega magama.” 
Teine vastas: "Olgu, heidame magama."

Nad heitsidki naisega magama. Kumbki nendest suudles ja kallistas naist ning siis tegid mõlemad seda korraga (Bogoras-Tan 1934: 135-139).

Grupiabielu vorm, mida on kirjeldatud selles jutus, kirjeldab peaaegu tõelist mitmemehepidamist. Pean ütlema, et mõnikord muutub grupiabielu kahe-kolme aasta pärast väga keeruliseks ning seda just naiste vahetuse tõttu. Iga "seltsimees naise kaudu" võtab enda juurde naiseks teise mehe naise. Elab temaga mõned kuud ja siis annab tagasi. Juhtub, et mees võtab naise enda juurde pikemaks ajaks või isegi alatiseks. Tänapäeval haarab grupiabielu peaaegu kõiki tšuktši perekondi.

\section{Kirjandus}

Богораз-Тан, Владимир 1934. Чукчи I. Ленинград: Издательство главсевморпути. 